+ In beeld

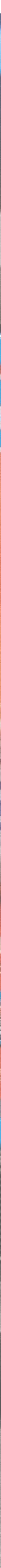


Fotograaf Marijke Stroucken was al bezig aan een serie met de zussen Miriam en Ruth toen de lockdown toesloeg. Ruth zag hoe Miriam, die al dementerende was, nog sneller achteruitging. 'Geen isolatie, laat dat niet meer gebeuren, dat moet de les zijn.'

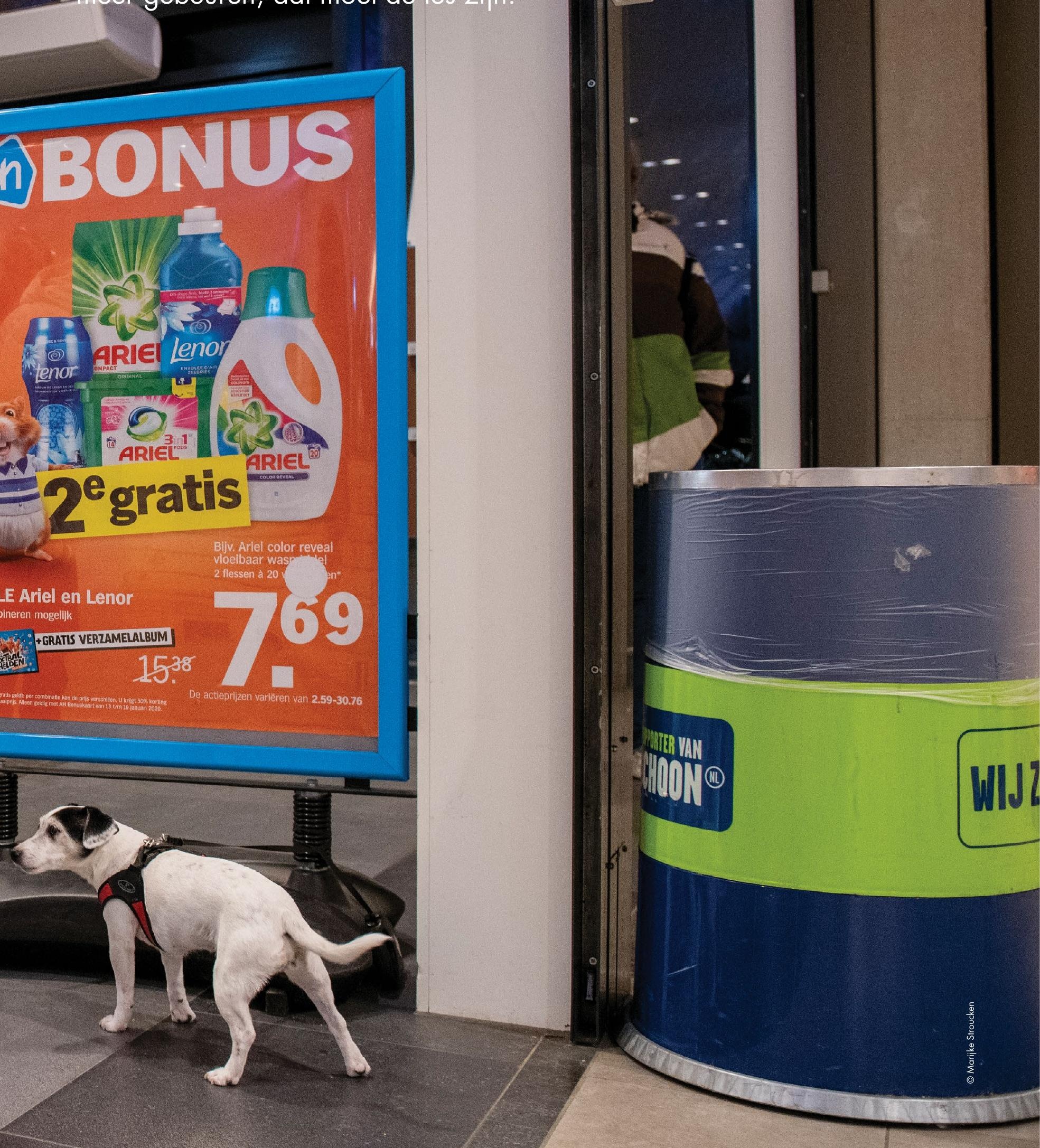

( 

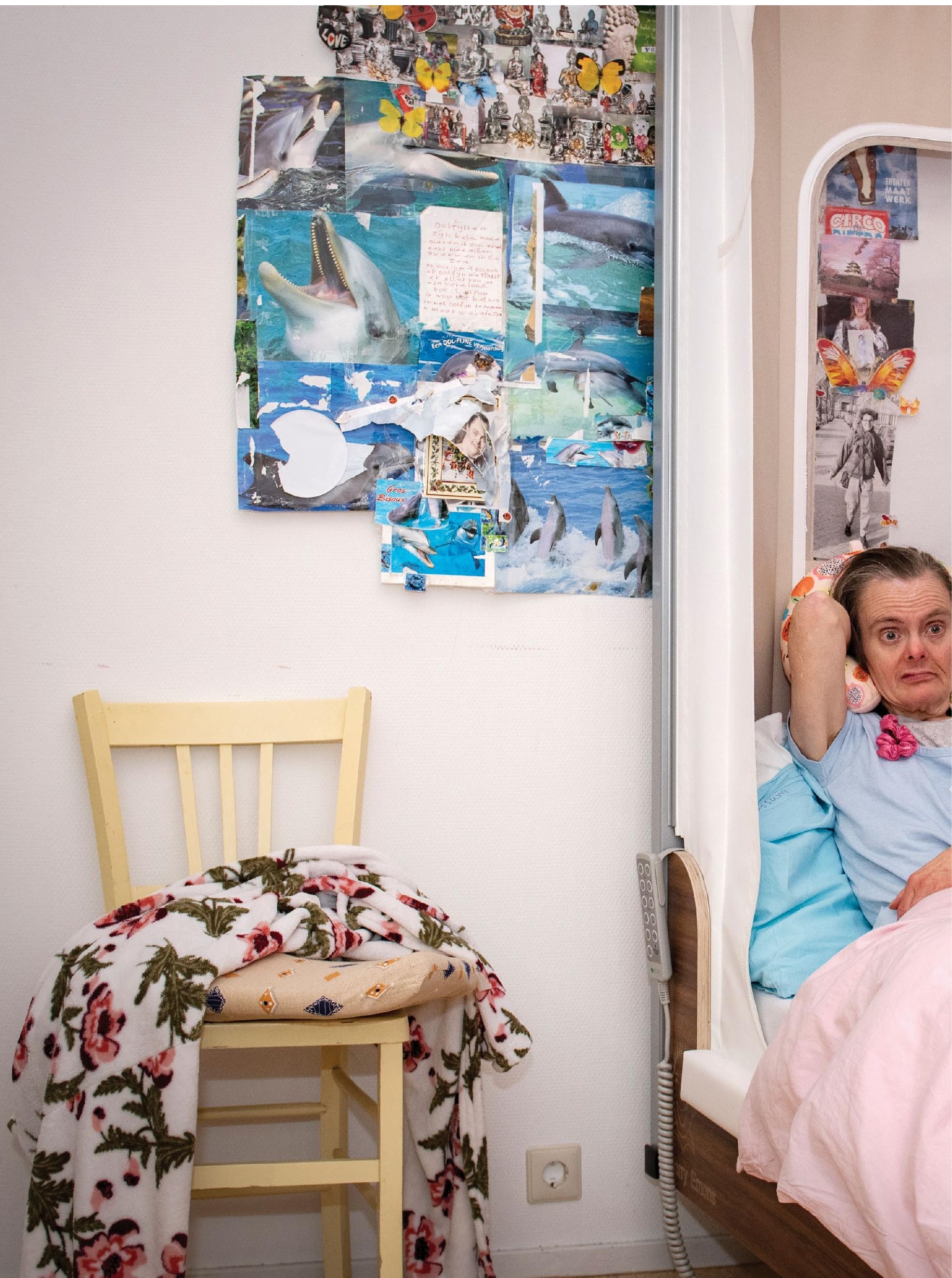


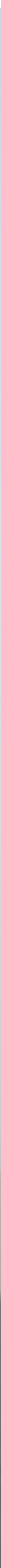




\section{+ In beeld}
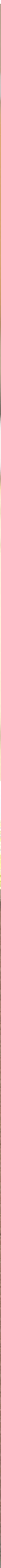


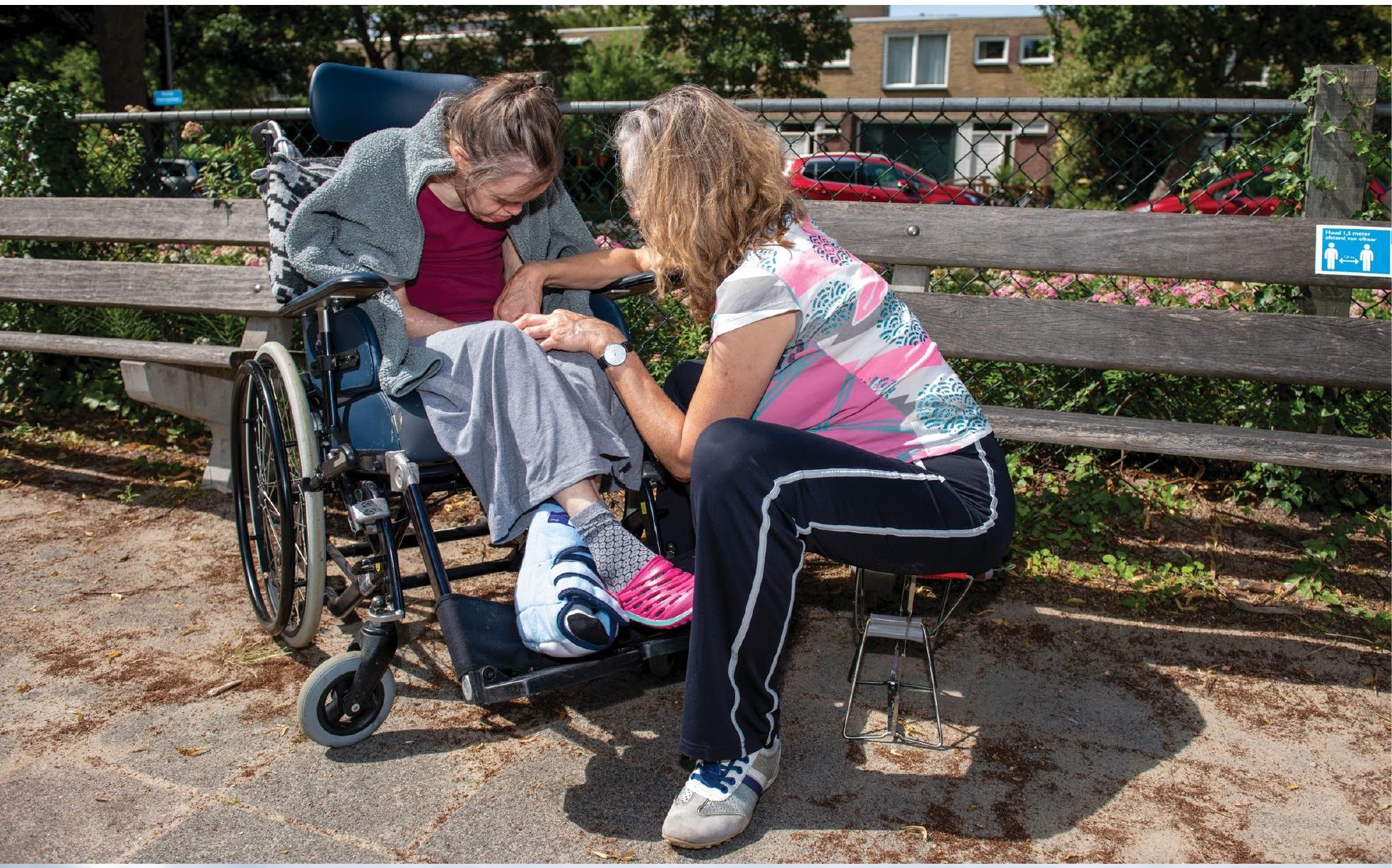

$7^{3} x^{2}$

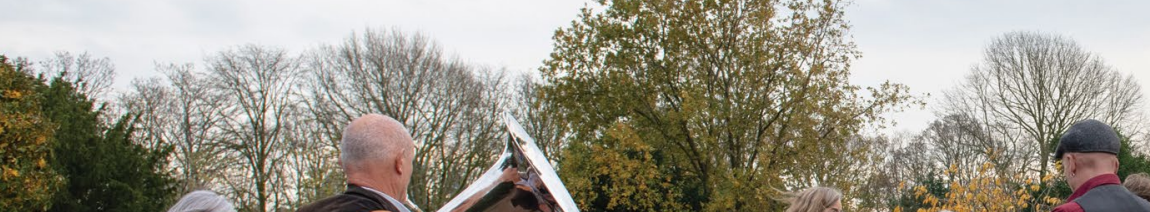

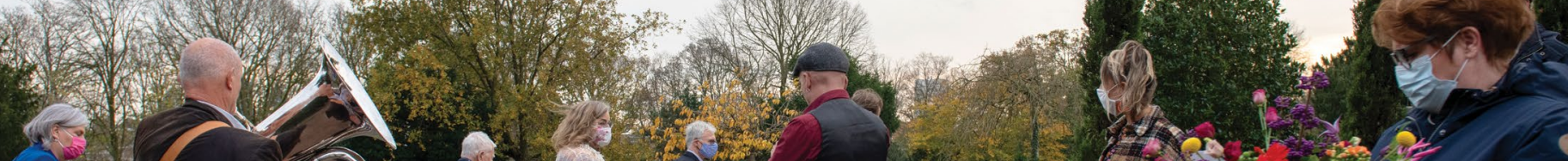

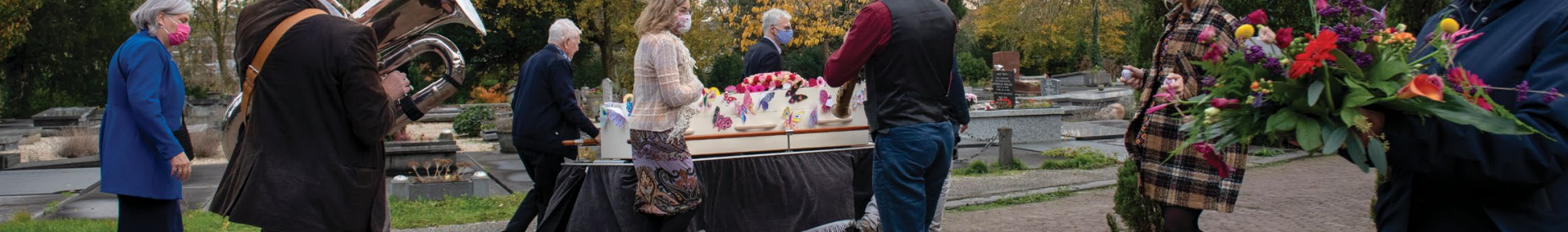




\section{+ In beeld}

(1) $140.5 \%$

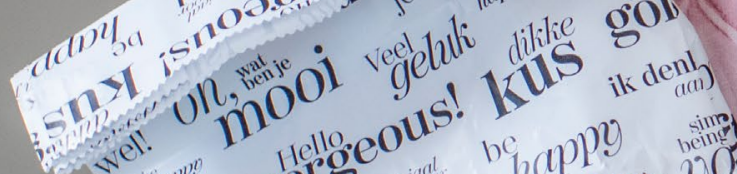

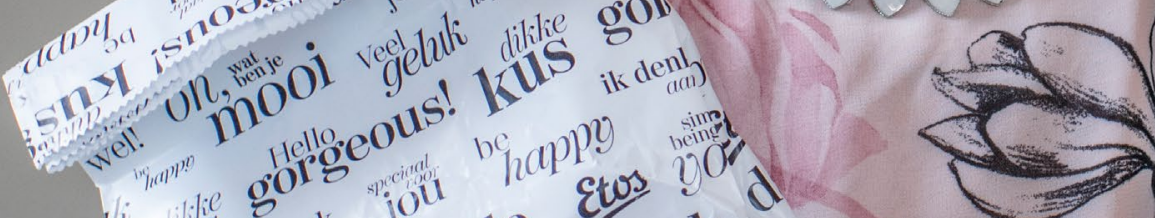

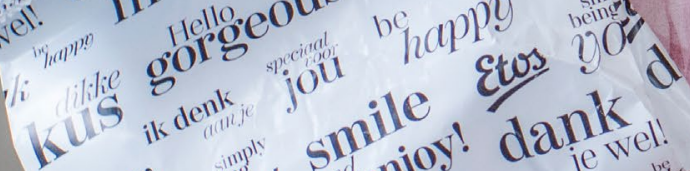

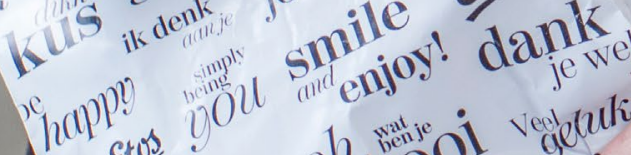

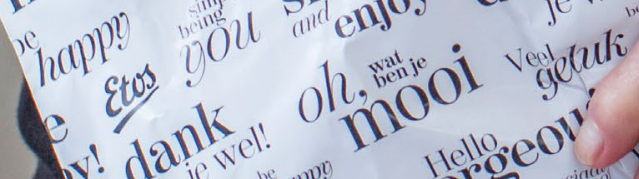

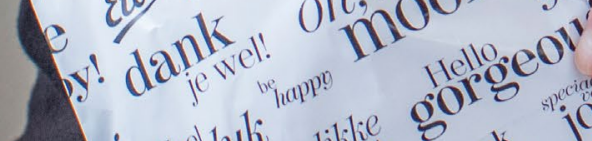

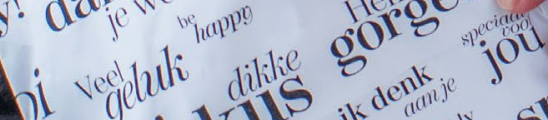

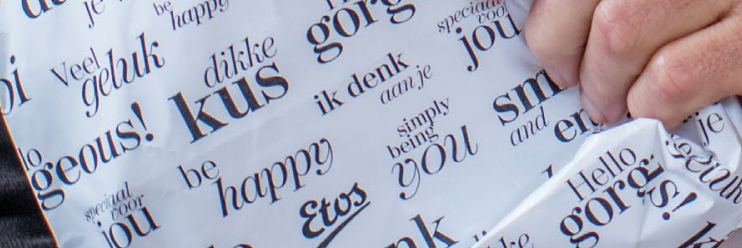

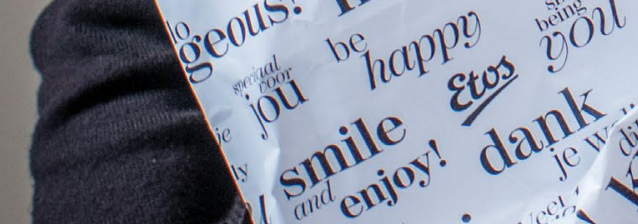
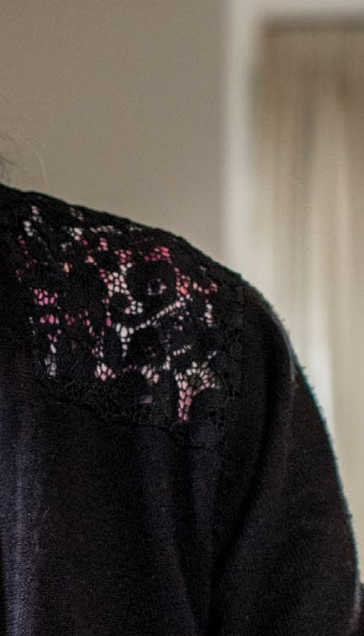


\section{'Door de lockdown is het allemaal heftiger geweest en is het sneller gegaan'}

\section{— Marijke Stroucken: 'Miriam ken ik al heel lang. Zij is de zus van Ruth en Ruth is de partner van een studievriend van mijn man. Zo lang ik mijn man ken, ken ik hen. Het is niet zo dat ik heel intens contact met Miriam had, maar ik zag haar geregeld als ze op bezoek was bij Ruth.'}

'Miriam was altijd een gezonde en ook bijzondere vrouw. Dat laatste niet omdat zij het syndroom van Down had, zij was echt bijzonder. Wanneer je haar ontmoette had zij altijd een glimlach op het gezicht en ze maakte deel uit van een theatergezelschap in Rotterdam. Ze was actrice, schreef ook eigen toneelstukken. Daarin was de hoofdrol voor haar zelf weggelegd, de prinses. Er kwam een boef in voor en een reddende ridder. Op verjaardagen speelden we soms mee in haar toneelstuk.

Miriam en Ruth hebben altijd een sterke band gehad. Toen Miriam slechter begon te worden - zij begon te dementeren - vroeg Ruth of ik Miriam wilde fotograferen. Gaandeweg werd duidelijk dat ik niet alleen Miriam portretteerde, maar ook een bijzondere zussenrelatie, die naarmate de dementie voortschreed, ook een moeder-kindverhouding werd. En toen werden we overvallen door COVID-19 en de beperkende maatregelen. We zagen Miriam, die ondanks haar dementie nog vrolijk was gebleven, opeens in twee, drie maanden enorm verslechteren.'

Ruth van Rossum: 'Ik wilde vooral nog wat mooie foto's van Miriam hebben, mijn twee jaar jongere zus. Want ik wist dat het dementieproces, dat in 2012 begon, tot de dood zou leiden. Ik zag Miriam heel vaak, ze kwam ook vaak logeren bij mij. Maar met de lockdown was dat voorbij, ik heb die periode als vreselijk ervaren. Mensen met dementie hebben vertrouwde structuren nodig. Miriam begreep dat beeldbellen niet. We hebben het geprobeerd met voor het raam staan, maar daar raakte ze ook van in de war. Nadat ik aandrong bij het verzorgingshuis mochten we elkaar zien op het parkeerterrein voor het huis, op afstand van elkaar. Dat was hartverscheurend, want de eerste periode herkende ze me nog, strekte ze haar armen naar me uit, zo van: kom dan! Maar dat kon niet. Gaandeweg zag ik dat zij sneller achteruitging. Ze is in die periode in een rolstoel terechtgekomen. Natuurlijk had de neergang zich al ingezet, maar ik ben ervan overtuigd dat het door de lockdown allemaal heftiger is geweest en sneller is gegaan. Het heeft maanden geduurd voordat ik haar weer van dichtbij mocht zien. Ik mocht toen met haar in de rolstoel wandelen. Dat moest met een medisch mondmasker, ze herkende mij niet. Pas toen het zo slecht ging dat men dacht dat ze doodging, mocht ik gewoon bij haar zijn op haar kamer. Je zal van mij geen kwaad woord horen over het verzorgingshuis. Daar werken fantastische, lieve mensen. $\mathrm{Zij}$ moesten zich ook aan de regels houden. Maar ik begrijp niet dat er niet al heel snel een landelijke taskforce is opgezet om manieren voor nabij contact te vinden. Om te voorkomen dat mensen zoals Miriam geïsoleerd zouden worden van hun familie. Want dat is inhumaan. Er gaan andere virussen komen. Zorg ervoor dat mensen als mijn zus nooit meer afgescheiden worden van hun dierbaren. Zorg dat er nabij contact kan zijn: oogcontact, omhelzing. Geen isolatie, laat dat niet meer gebeuren, dat moet de les zijn.'<
Marijke Stroucken fotografeerde tot 2005 voor haar plezier met een analoge fotocamera. In dat jaar kreeg zij van haar man een digitale camera. 'Maar het lukte me maar niet om mooie foto's te maken', zegt zij. 'Het ontbrak me aan kennis over de techniek. Ik ben toen een aantal cursussen gaan volgen in Rotterdam. Die waren nuttig, maar ik wilde meer, ik was hooked. Ik ben verder gaan informeren bij de Fotoacademie. Daar zei men, waarom volg je hier de opleiding niet. Ja, waarom niet? Ik kon instromen in het tweede jaar en ben afgestudeerd in Amsterdam.'

Hoewel zij eigenlijk een andere carrière had - als consultant en manager - besloot zij om te gaan werken als documentair fotograaf. Zij kon fulltime aan de slag bij Het Parool, maar na drie maanden begreep zij dat het dagelijks snel even ergens een foto maken niet haar ding was. Marijke wil zich verdiepen in het onderwerp en er langere tijd in investeren. En dat doet zij nu ook. Aanvankelijk koos zij een onderwerp, begon met fotograferen en na afloop bood zij de serie met wisselend succes ergens aan. Tegenwoordig peilt zij van tevoren de interesse en probeert zij het project voorgefinancierd te krijgen. Zij publiceert in verschillende bladen en zij exposeert in binnen-en buitenland.

www.marijkestroucken.nl 